\title{
The importance of human resources within the strategic direction and organizational success
}

\author{
Maria Magdalena CRIVEANU \\ University of Craiova, Craiova, Romania \\ mag_da64@yahoo.com \\ Silviu CÂRSTINA \\ University of Craiova, Craiova, Romania \\ silviu.carstina@yahoo.com
}

\begin{abstract}
The economic environment in Romania faces a series of turbulences generated by the political and social environment, and an avalanche of changes and fluctuations can destabilize the activity of an organization. As a consequence, organizations need to be as flexible as possible, able to adapt and integrate any kind of change. In this regard, a manager must study the type of organizational culture found at the company level and the way it can influence the results of the organization. A detailed investigation method belongs to researchers Kim Cameron and Robert E. Quinn who have proposed a model of culture analysis that involves identifying the type of dominant culture and recognizing behaviours which are specific to organizational dimensions such as: organizational leadership, employee management, strategic direction, or criteria of success. The present paper aims to analyze the type of objectives managers set for their employees (namely the strategic emphases dimension) and how they measure results (the criteria of success dimension) at the level of a private company in Romania. Thus, following the application of the Organizational Culture Assessment Instrument proposed by the two authors, we identified the type of culture that characterizes the two dimensions, the connection established between them, the possible inconsistencies between the present and the desired situation as perceived by the employees, as well as the type of correlation between the economic and financial indicators and the cultural profile that identifies the success. Such an analysis is very useful as it identifies a series of inconsistencies between the way the goals are set by the managers and the way to measure success, the two dimensions being in a tight interdependence. Thus, a discrepancy between the two dimensions can lead to conflicts at the organizational level, with the manager having a tendency to set a series of objectives (e.g. individual objectives), in fact pursuing other results (such as team results). In this respect, the aim of this paper is to identify a correlation between the objectives targeted by the manager, the way he measures success and the satisfaction of the employees with the current situation.
\end{abstract}

Keywords: organizational culture, human resource, organizational leadership, management of employees, strategy.

\section{Introduction}

Organizational culture is a recent theme approached by Romanian entrepreneurs, but occupies an important place in specialty literature. This paper aims to highlight the importance of knowing the type of culture in order to make new strategic decisions. Many researchers have developed tools to analyze organizational culture which serve managers who are in charge with culture change. They combined qualitative and quantitative methods in creating a more representative analysis model and developed modern patterns of interpretation. 


\section{Literature review}

The current context requires organizations a very alert rhythm. They must constantly adapt to change, so that managers need to create a culture that is more flexible and environmentally oriented. The Romanian companies developed through the last half of this century an organizational culture based on negative motivation and on inhibiting any innovation attitude (Bratianu 2015).

This study aims at analysing the status of the types of culture at the level of the strategic direction and success criteria following the model of a private company, mainly because "during the financial crisis of 2008-2009, the country's labour force suffered major changes" (Marcu et. al., 2015). Some authors underline that even "the universities have to adapt the curriculum to the needs of the economy" (Marcu \& Meghisan, 2014). The father of modern management, Peter Drucker, concluded that "We are in one of those great historical periods that occur every 200 or 300 years when people don't understand the world anymore, and the past is not sufficient to explain the future" (quoted in Cameron and Quinn 2011). According to researchers "organisational learning, development and planned change cannot be understood without considering culture as the primary source of resistance to change" (Schein 1992). He craves this resistance, opposition or reluctance to change in the form of anxiety (2009). For Schein, anxiety is a mix of fears that work when the employee is put in a position to learn something new, to the detriment of old knowledge (Schein 2009). As a consequence, "it is important to identify all the organizational resistances, and to develop strategies to overcome them" (Bratianu 2015). Furthermore, the type of culture found at the level of a company can shape strategic thinking, thus contradicting the organization's industrial strategy: "Strategic thinking is about creating and implementing strategies to win a generic competition from a battlefield to a business environment" (Bratianu 2007 ). An important aspect is that researchers have approached the strategy during the last two decades in a modern manner, associating it with the notion of knowledge "because knowledge has been increasingly seen as a strategic weapon and a competitive factor" (Kasten 2007). As a matter of fact, "knowledge represents the most important source of wealth" (Bratianu 2015). "Companies that disregard the importance of knowledge as the main driver of performance will have a difficult time competing in a dynamic global environment or even surviving" (Bratianu 2015).

The economic and financial indicators taken into account for the correlation analysis in terms of organizational culture are indicators that reflect the level of economic and financial performance of the firm. The economic and financial performance of an enterprise has become an objective for most managers in our country and beyond.

Until recently, they were focusing on getting the most profit, so in other words, they looked at efficiency only in terms of efficiency, now the best positioning of the business has become their main purpose.

Economic and financial performance is defined as "a function of two variables efficiency and effectiveness, the combination of them reflecting the performance level" (Bușe et al. 2007).

Porter M. believes that "performance depends on the ability of an enterprise to create value for its customers" (Porter 1986). 
Niculescu M. defines the concept of performance based on the criteria that define it, efficiency and effectiveness, but they are adapted to the conditions of the economic environment, as follows:

a) in the period 1960 - 1970 for defining the concept of performance were used the indicators that define the size of the company: turnover, total assets;

b) the period from 1970 to 1980 is defined in terms of profitability indicators: net

PICBE $\mid 231$ profit, profit per share;

c) between 1980 and 1990, the issue of the liquidity indicators emitted by the economic activity, expressed by cash-flow indicators;

d) the period 1990-2001 focused on the creation of value expressed through: cashflow return of investments, economic added value, market added value;

e) after 2001, the emphasis is on creating value that is subordinated to the goal of sustainable development (Niculescu 1998).

Erich A. Helfert views performance as "a way to measure an enterprise's business through the most efficient use of financial resources, business profitability, enterprise finance problems (if appropriately chosen)" (Helfert 2011).

\section{Methodology}

The analysis tool belongs to Kim Cameron and Robert E. Quinn, who propose an analysis model for 6 cultural dimensions of the organization based on a questionnaire, namely the Organizational Culture Assessment Instrument. At the same time, after applying the questionnaire, the cultural profile of the company is outlined, emphasizing any differences between what is found at the company level and what the employees want to experiment or consider beneficial for the organization. The two authors fit an organization into one of four types of culture, which according to studies are the most representative in the characterization of an enterprise: hierarchical culture, clan culture, market culture, adhocracy culture.

The questionnaire was applied to 100 respondents, of which 27 women and 73 men within the private company S.C. Softronic S.R.L. At the same time, for our study to be consistent we used data processing by means of SPSS, using the Pearson index. The indicators selected for the case study can be grouped as follows: indicators reflecting the level of production and marketing activity (turnover and output of the exercise) and indicator reflect profitability (operating profit, gross operating surplus, net profit, economic profitability ratio of assets and the rate of financial return).

Turnover is defined as the indicator that reflects the market share of the enterprise on the economic sector in which it operates.

The output of the exercise reflects all the assets made by the enterprise for a certain period of time and consists of the production sold, the variation of the production stock and the immobilized production.

The difference between operating income and operating expenses reflects the operating profit, an indicator that is often confused with the gross operating surplus, the latter being distinguished by its monetary nature, taking into account only the income and the monetary expenses from the activity of operation.

The economic return on total assets determined as the ratio between gross profit 
and total assets expresses the efficiency with which the assets were used during the course of the business and the rate of financial return expresses the enterprise's ability to create value for its shareholders.

All of these indicators vary from time to time depending on the level of efficiency and effectiveness of the firm, an important role in this respect, not only in terms of technology assets or capital, but also the human resources of the enterprise.

PICBE | 232

The paper aims at following the validation/invalidation of the following assumptions:

Assumption 1: Romanian private companies are mostly characterized by the adhocracy culture, as managers primarily aim at achieving results, increasing their market shares, increasing productivity, enhancing the turnover, speculating opportunities and meeting challenges and novelties. A less important aspect is related to the human resource, which is awarded a lower importance compared to the quantitative goals of the organisation.

Assumption 2: a direct positive relationship is established between the strategic direction and success criteria, pointing to an organisational consistency between the proposed goals and their measurement method.

Assumption 3: the company is not characterized by internal conflicts, and employees do not show a strong tendency to change. Thus, the organization is characterized by the absence of conflicts, with a beneficial work environment, as the rules are accepted by employees.

Assumption 4: a very strong, direct and positive relation is seen between the results desired at the level of the strategic direction and the results desired at the level of success criteria. To this purpose, we may say that the employees' wishes are a major clue on a new direction of action, as employees represent a genuine source of information at the organizational level.

\section{Results and discussions}

In the following, we analysed the status of the types of cultures at the level of the 2 dimensions, as follows:

The first dimension refers to the type of culture that characterizes the company's strategy. The red line is the current culture as identified at the time of applying the questionnaires, while the blue line represents the culture that employees consider closest to their needs. The higher the score in a culture, the stronger the culture. Strong cultures appear as a result of a homogeneous activity, where actions are very clear set, responsibilities and activities are very well determined. 


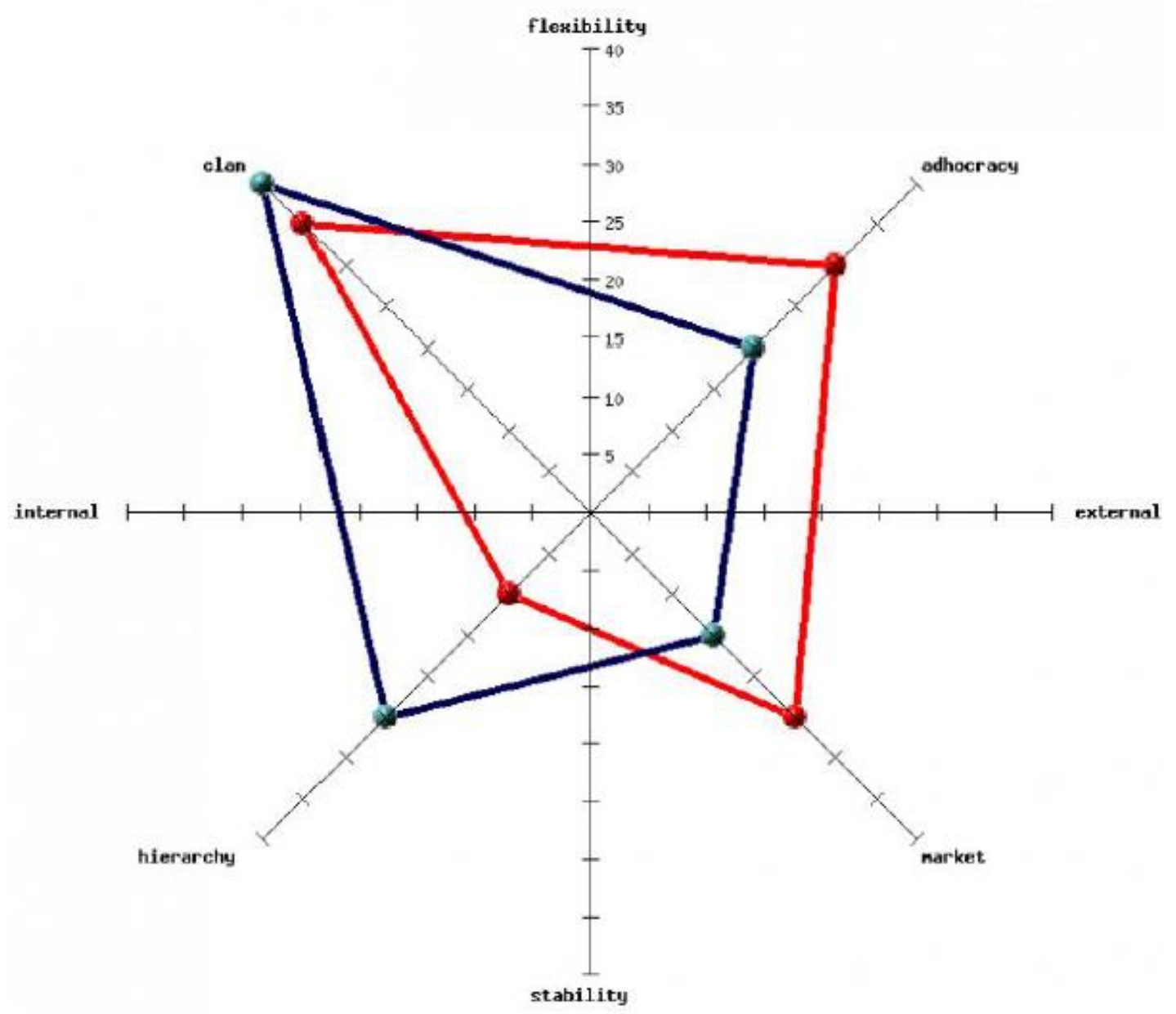

Figure 1. Strategic Emphases

Source: Authors' own research.

As seen in the chart describing the strategic dimension, focus is given on human resource development, as trust, openness or engagement are the basic pillars of organizational development. All these features belong to the clan culture, which gets 35 points. 5 points away we find the adhocracy culture (30 points), so that a different side of the strategy deals with meeting new challenges, prospecting new opportunities, with special importance being assigned to experiments and novelty. The market culture aims at achieving goals and increasing the market share (25 points), while stability and control are only representative to an extent of $10 \%$ (hierarchy culture - 10 points).

Following the analysis of this dimension, we suggest that the manager should introduce a new mix of cultures, also assimilating the employees' wishes. Thus, the incongruities between the two quadrants suggest an organizational conflict regarding the company's strategy. Thus, employees want more stability (with the hierarchy culture 
having a 15-point increase), the adhocracy culture must be diluted regarding the employees' needs for safety (the adhocracy culture decreases by 10 points), while the market culture suggests the same direction for action. The focus on human resource keeps defining the company's strategy, with the employees even suggesting an enhancement thereof, and a 5-point increase for the clan culture.

PICBE | 234

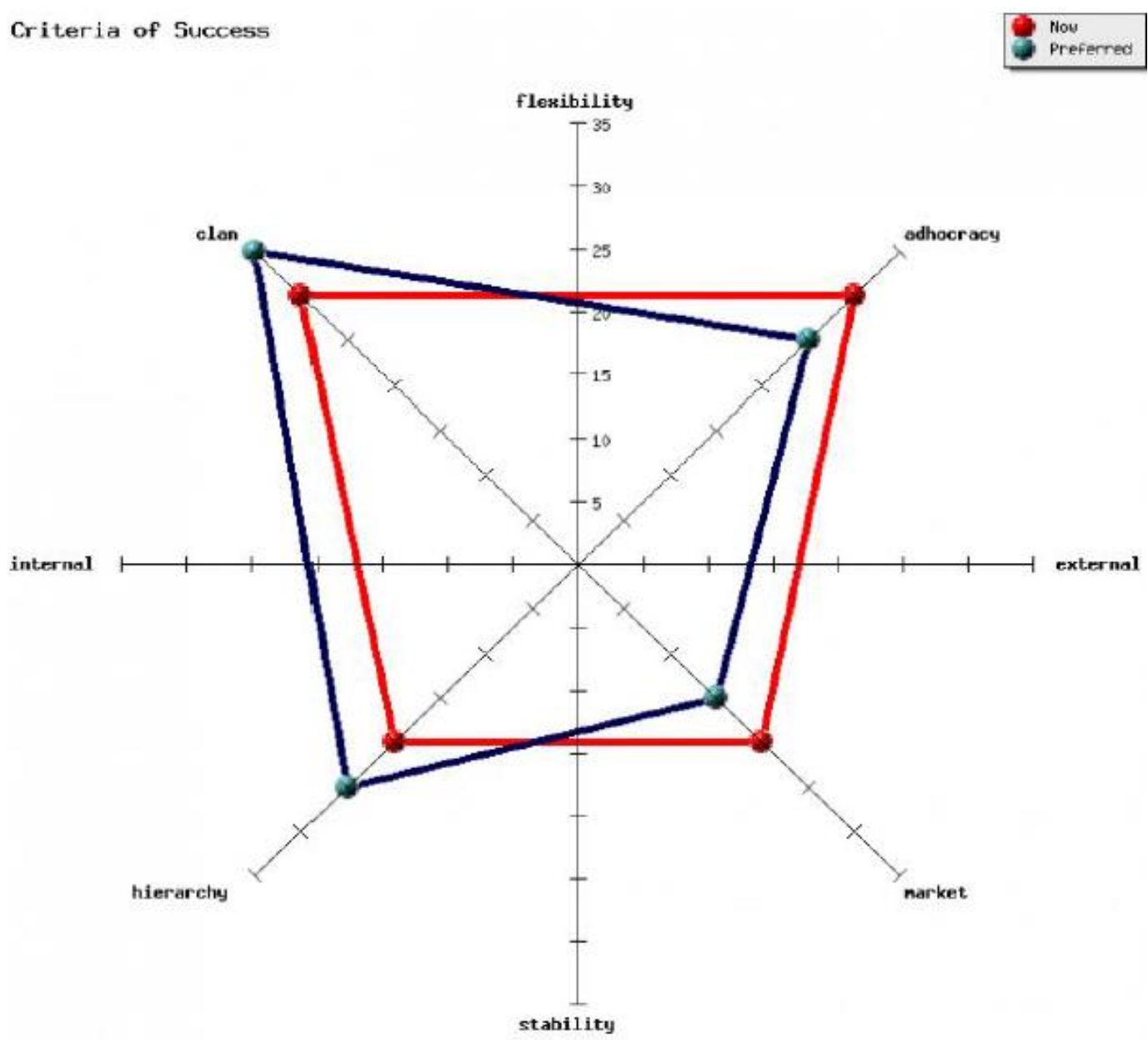

Figure 2 Criteria of success

Source: Authors' own research.

In the following, we have also analysed the dimension regarding the success measurement method. The match between the two dimensions also aimed at identifying an organizational consistency between the two dimensions. This combination may help identify gaps between the strategies and success measurement, which would result in incongruities in the company. Thus, success should be measured and expressed as the strategic direction was outlined. Thus, if the strategy aims at reaching quantitative goals, such as increasing productivity or turnover enhancement, success must be measured based on the same parameters. Upon scoring the respondents' answers, we notice that the 
organization defines success from the perspective of the two types of culture, i.e. adhocracy culture and clan culture (both having 30 points). Thus, human resource development remains the asset of success in the organization, thus following the strategic line, while novelty is a different criterion for success. At the same time, market share increase and efficiency are significant components in defining success, with each of the two having 20 points. It should be noticed that the difference between the two states does not exceed 10 points in either case, so that a new culture mix need not be introduced. All differences have positive and negative 5-point values, which does not symbolize an organizational gap.

\section{The validation of the hypotheses of the scientific research}

Assumption 1, that private companies are focused on enhancing performance indicators, and the focus on human resource is depreciated in contrast with this mercantile spirit is invalidated pursuant to the analysis of results at the 2 dimensions. Thus, at the level of strategic direction, we notice that the prevailing type of culture is clan culture, with human resource development lying at the core of the managers' interest, whose strategy consists of training such resource. Even though the organizational environment is dominated by the combination between the features of clan culture and adhocracy culture at the level of the second analyzed dimension, i.e. success criteria, the same enhanced importance assigned to human resource is also seen here, resulting in the invalidation of assumption 1.

Assumption 2 needed statistical and mathematical processing by means of SPSS for purposes of validation or invalidation. Considering the goals proposed for this assumption, i.e. the relationship between strategic direction and success criteria, we concluded that, in order to emphasize the types of connections between the two, we should rely on the actual results obtained at the level of strategic direction and a range of result indicators: turnover, current production, operating profit, gross operating earnings, net result, economic rate of return and financial rate of return.

Before actually calculating the correlation index, we analysed the descriptive statistics reflected by the software, with the indicators being presented in the following table:

Table 1. Descriptive statistics

\begin{tabular}{|l|r|r|r|}
\hline & \multicolumn{1}{|l|}{ Mean } & \multicolumn{1}{l|}{ Std. Deviation } & N \\
\hline Turnover (CA) & 77603661.60 & $2.448 \mathrm{E} 7$ & 5 \\
\hline Current output (Qe) & 79919194.60 & $2.466 \mathrm{E} 7$ & 5 \\
\hline Operating profit (Pe) & 81048236.60 & $2.850 \mathrm{E} 7$ & 5 \\
\hline $\begin{array}{l}\text { Gross operating earnings } \\
\text { (EBE) }\end{array}$ & 20714318.00 & 8927850.869 & 5 \\
\hline Net earnings (Pn) & 2137255.60 & 1607440.626 & 5 \\
\hline ROA & $54.104000 \%$ & $17.3926545 \%$ & 5 \\
\hline ROE & $4.514000 \%$ & $3.3192966 \%$ & 5 \\
\hline Current state & 25.00 & 10.801 & 4 \\
\hline
\end{tabular}

Source: Authors' own research. 
For the correlation analysis to be meaningful, the average resulting within the variables should exceed the standard deviation. In our case, the significance of the resulting correlations is confirmed statistically, having observed this principle.

By means of the Pearson index used in the SPSS software, we demonstrated the types of relations existing between the strategic direction and success criteria, with the correlation being established in the following table:

PICBE | 236

Table 2. Pearson Correlation

\begin{tabular}{|c|c|c|c|c|c|c|c|c|}
\hline & & $\begin{array}{l}\text { Turnover } \\
\text { (CA) }\end{array}$ & $\begin{array}{l}\text { Current } \\
\text { output (Qe) }\end{array}$ & $\begin{array}{l}\text { Operating } \\
\text { profit (Pe) }\end{array}$ & \begin{tabular}{|l} 
Gross \\
operating \\
earnings \\
(EBE)
\end{tabular} & $\begin{array}{l}\text { Net } \\
\text { earnings } \\
\text { (Pn) }\end{array}$ & ROA & ROE \\
\hline \multirow[t]{3}{*}{ Current state } & \begin{tabular}{|l} 
Pearson \\
Correlation
\end{tabular} & .370 & .219 & \begin{tabular}{|l|}
-.009 \\
\end{tabular} & .607 & .663 & .400 & .685 \\
\hline & Sig. (2-tailed) & .630 & .781 & .991 & .393 & .337 & .600 & .315 \\
\hline & $\mathbf{N}$ & 4 & 4 & 4 & 4 & 4 & 4 & 4 \\
\hline
\end{tabular}

*. Correlation is significant at the 0.05 level (2-tailed).

**. Correlation is significant at the 0.01 level (2-tailed).

Source: Authors' own research.

Out of seven result indicators, we obtain that a significant correlation was only obtained for the gross operating earnings, the net earnings and the financial rate of return.

Considering the level of these correlations, we may say that assumption 2 may be partially validated, also analysing the type of indicators where a correlation was established. We conclude by saying that a connection was found between cash flow indicators and the indicators reflecting the company's capacity to generate earnings for its shareholders.

The cash flow indicators may be the gross operating earnings, which are frequently mistaken with the operating earnings; the distinction is that gross operating earnings are classified by specialists as the potential cash flow generated by the company's operating activity.

The shareholders' earnings may be estimated in terms of net earnings, which are the basis of distribution of dividends, as well as in terms of the rate of financial return, which is of major interest for the shareholders, reflecting the efficiency of the company's use of equity.

Assumption 3 is invalidated, as the work environment is effervescent, affected by a range of conflicts expressed by the employees. Thus, the strategy implies a range of imbalances suggested by the gap for 3 of the 4 types of culture, i.e. adhocracy culture, market culture and hierarchy culture. 
Table 3. The gap for the strategic direction dimension

\begin{tabular}{|l|r|r|r|}
\hline $\begin{array}{l}\text { TYPE } \\
\text { CULTURE }\end{array}$ & CURRENT STATE & DESIRED STATE & GAP \\
\hline CLAN & 35 & 40 & +5 \\
\hline ADHOCRACY & 30 & 20 & $\mathbf{- 1 0}$ \\
\hline MARKET & 25 & 15 & -10 \\
\hline HIERARCHY & 10 & 25 & $\mathbf{+ 1 5}$ \\
\hline
\end{tabular}

The employees reject the company's openness to risk taking, as they are mostly conservative, restrained and sceptical regarding the management's advance to novelty and challenge. The most representative change refers to stability, safety, predictability, which are frequently invoked by employees as meaningful in tracing a strategy.

If a clear tendency of employees to change is seen in terms of strategic direction, the atmosphere is different for the second dimension, as employees seem to tolerate the current situation, and the differences between the two states are less than 10 points.

Assumption 4, as assumption 2, needed data processing by means of SPSS, also using the Pearson index.

This assumption presents the relationship between strategic direction and the company's success indicators, but now we considered the results desired by the persons interviewed in the questionnaire. In order to express the company's success indicators, we maintained the indicators presented in assumption 2.

The correlation level established with the Pearson index is confirmed, as for assumption 2, by means of descriptive statistics, as reflected in the following table:

Table 4. Descriptive statistics

\begin{tabular}{|l|l|l|l|}
\hline & Mean & Std. Deviation & $\mathbf{N}$ \\
\hline Turnover (CA) & 77603661.60 & $2.448 \mathrm{E} 7$ & 5 \\
Current output (Qe) & 79919194.60 & $2.466 \mathrm{E} 7$ & 5 \\
Operating profit (Pe) & 81048236.60 & $2.850 \mathrm{E} 7$ & 5 \\
Gross operating earnings & 20714318.00 & 8927850.869 & 5 \\
(EBE) & & & \\
Net earnings (Pn) & 2137255.60 & 1607440.626 & 5 \\
ROA & $54.104000 \%$ & $17.3926545 \%$ & 5 \\
ROE & $4.514000 \%$ & $3.3192966 \%$ & 5 \\
Desired state & 25.00 & 10.801 & 4 \\
\hline
\end{tabular}

Source: Authors' own research.

For all variables, descriptive statistics shows an average higher than the standard deviation, which is why correlation analysis is classified as representative.

After analysing the descriptive statistics, we determined the correlation between the desired result indicators, specific to strategic direction, and the economic and financial success indicators of the company. 
The established correlation is reflected in the table below:

Table 5. Pearson Correlation

\begin{tabular}{|l|l|l|l|l|l|l|l|l|}
\hline & Turnover (CA) & $\begin{array}{l}\text { Current output } \\
\text { (Qe) }\end{array}$ & $\begin{array}{l}\text { Operating } \\
\text { profit (Pe) }\end{array}$ & $\begin{array}{l}\text { Gross } \\
\text { operating } \\
\text { earnings } \\
\text { (EBE) }\end{array}$ & $\begin{array}{l}\text { Net earnings } \\
\text { (Pn) }\end{array}$ & ROA & ROE \\
\hline \multirow{2}{*}{$\begin{array}{l}\text { Desired } \\
\text { state }\end{array}$} & $\begin{array}{l}\text { Pearson } \\
\text { Correlation }\end{array}$ & .710 & .830 & .879 & .526 & -378 & .605 & .356 \\
\cline { 2 - 9 } & Sig. (2-tailed) & .024 & .018 & .016 & .047 & .622 & .039 & .644 \\
\cline { 2 - 9 } & N & 4 & 4 & 4 & 4 & 4 & 4 & 4 \\
\hline
\end{tabular}

*. Correlation is significant at the 0.05 level (2-tailed).

**. Correlation is significant at the 0.01 level (2-tailed).

Source: Authors' own research

Considering the correlation results established by the Pearson index, assumption 4 is validated and, hence, we may say that a very strong, direct and positive relationship exists between the results desired for the strategic direction dimension and those desired for the success criteria. Therefore, we may say that the employees' wishes are a major clue on a new direction of action, as employees represent a genuine source of information at the organizational level.

\section{Conclusion}

In conclusion, we see that private companies tend to enhance the importance of human resource, relying on cohesion and community, with a major part being assigned to human resource development. Softronic places human resources before financial aspects, as its global strategy aims at ensuring the cohesion of work teams. At the same time, we observe that the analysed company is effervescent in terms of strategic direction. The major differences signalled by employees outline the managers' tendency to expose themselves to risk. Such an attitude may generate distrust against the Romanian economic environment. Thus, managers should be more understanding regarding the employees' need for safety and reconfigure their strategy so that human resources are protected from the turbulences of the economic environment.

The analysis of data regarding the validation of assumption 2 allows us to say that there is a direct, positive, but partial relationship between strategic direction and success criteria, which indicates the existence of organizational coherence between the proposed goals and their measurement method. In terms of the obtained results, assumption 2 was validated partially, with a meaningful correlation for cash flow indicators; the used indicators were the gross operating earnings and the indicators expressing earnings generated by the company for its shareholders, such as net profit and the financial rate of 
return.

The validation of assumption 4 considered the relationship between the strategic direction and the company's success indicators; the conclusion was reached that there is a strong, direct correlation between the desired results and the company's success indicators, which is why we ended by saying that the employees' wishes are an important clue on a new direction for action, as they are a genuine source of information at the organizational level.

\section{References}

Bratianu, C. \& Bolisani, E. (2015). Knowledge strategy: An integrated approach for managing uncertainty. In Garlatti, A. \& Massaro, M. (Eds.). Proceedings of the 16th Conference on Knowledge Management, University of Udine, Italy, 3-4 September 2015 (pp. 169-177). Reading: Academic Conferences and Publishing International. Bratianu, C. (2007). Thinking patterns and knowledge dynamics. In B. Martins \& D. Renyi (Eds.). Proceedings of the 8th European Conference on Knowledge Management. Consorci Escola Industrial de Barcelona, Spain, 6-7 September 2007. Vol.1, pp.152156. Reading, UK: Academic Conferences Ltd.

Burdus, E., Caprarescu Gh., Androniceanu A., Miles M.(2000). Managementul schimbarii organizationale, Editura Economica, Bucharest.

Bușe L, Siminică M, Cîrciumaru D, Marcu N, Analiza economico-financiară a firmei, Editura Sitech, Craiova, 2007

Cameron, Kim S., Quinn Robert E.(2011). Diagnosing and changing organizational cultureBased on the Competing Values Framework, Jossey-Bass, A Wiley Imprint.

Cameron, Kim S., Downsizing, Quality, and Performance.(1995). In Robert E. Cole (ed.), The Fall and Rise of the American Quality Movement. New York: Oxford University Press.

Cameron, Kim S. (1997). Techniques for Making Organizations Effective: Some Popular Approaches. In Daniel Druckman, Jerome E.Singer, and Harold Van Cott (eds.), Enhancing Organizational Performance.Washington, D.C.: National Academies Press.

Circiumaru D, Siminica M, Marcu N. (2010). A study on the return on equity for the Romanian industrial companies, Analele Universitatii din Craiova.

Colquitt, J., Lepine, J.A., Wesson, M.J.(2010). Organizational behavior:Essentials for improving and commitment. Boston: Mc graw-Hill Irwin.

Helfert E.A, Tehnici de analiză financiară, ediția 11, BMT, Publishing House, 2011

Gordon, G. G.(1985). The Relationship Between Corporate Culture and industry Sector and Corporate Performances. In Ralph H. Kilmann and Associates, Gaining Control of the Corporate Culture. San Francisco: Jossey-Bass.

Hofstede, G., Hofstede, G.J. and Minkov, M.(2010). Cultures and Organizations: software of the mind:intercultural cooperation and its importance for survival ( $3^{\text {rd }}$ edition), New York, McGraw Hill.

Kasten, J. (2007) "Knowledge strategy and its influence on knowledge organization”, North American Symposium on Knowledge Organization, Vol. 1.

Marcu, N., Meghisan, G. M., \& Ciobanu, M. C. (2015). Research on Romanian Labour Market Dynamics. REVISTA DE CHIMIE, 66(9), 1540-1544. 
Marcu, N., \& Meghisan, G. M. (2014). Strategies for Better Integrate Youngsters within Romanian Companies in the Context of Economic-financial Crisis. Procedia Economics and Finance, 8, 459-465.

Niculescu M., Diagnostic Global-Strategic, Ed. Economică, București, 1998

Porter, M.E. , Competition in Global Industries, Harvard Business School Press, Boston, 1986

Siminica M, (2010). Diagnostic financiar al firmei, Ed. Sitech.

PICBE | 240

Schein E.H, (1985). Organizational Culture and leadership: A dynamic view, Jossey-Bass, San Francisco.

Schein E.H, (1992). Organizational Culture and leadership, Jossey-Bass, San Francisco.

Schein E.H.,(2009). The corporate culture survival guide, New and revised edition, JosseyBass a Wiley Imprint.

Peters, Thomas J. and Waterman Robert H. Jr. (1982). In Search of Excellence, Warner Books Edition.

*** Financial and accounting statements of Softronic 